\title{
Colonic perforation caused by the inadvertent trapping of mucosa in a retrieval net
}

Colonoscopy is a common procedure for the diagnosis and treatment of a wide range of conditions [1]. Serious complications are uncommon with a pooled overall serious adverse event rate of 2.8 per 1000 procedures.

A 72-year-old woman underwent colonoscopy in order to remove a large sigmoid polyp ( $\bullet$ Fig. 1 a). The polypectomy was performed without complication $(\checkmark$ Fig. 1b) and a standard retrieval net was deployed to retrieve the specimen. The first retrieval attempt was ineffective and, as a result of this, the nurse closed the net quickly. As the net was being retracted, a small amount of mucosa was trapped within its mesh ( Fig. $1 \mathbf{c}, \mathbf{d}$ ). When the net was drawn back into the distal end of the sheath, a small piece of the colonic wall was cut off in a "guillotine effect." After the second attempt the polyp was retrieved but a small perforation, with mild bleeding, was seen on the opposite wall of the colon ( Fig. 1 e). The perforation was treated by placement of endoscopic clips ( Fig.1f) and the patient was discharged 5 days later.

Colonic perforation during colonoscopy may result from mechanical forces on the bowel wall, barotrauma, or as a direct result of therapeutic procedures [1]. The rate of perforation is generally less than $0.1 \%$, but may be higher if the colonoscopy is performed for an indication other than screening. Surgical consultation should be obtained in all cases although endoscopic repair using either standard or over-the-scope clips has proved to be effective for closure of many colonic perforations $[2,3]$.

Until now, there have been no reports of iatrogenic colonic perforation due to the use of a retrieval net [4]. This report shows that perforation of the colon can occur in the most unexpected way, even using devices that are considered safe. While performing a polypectomy, both doctors and nurses must maintain high levels of attention as complications can occur, even when least expected.

Endoscopy_UCTN_Code_CPL_1AJ_2AC
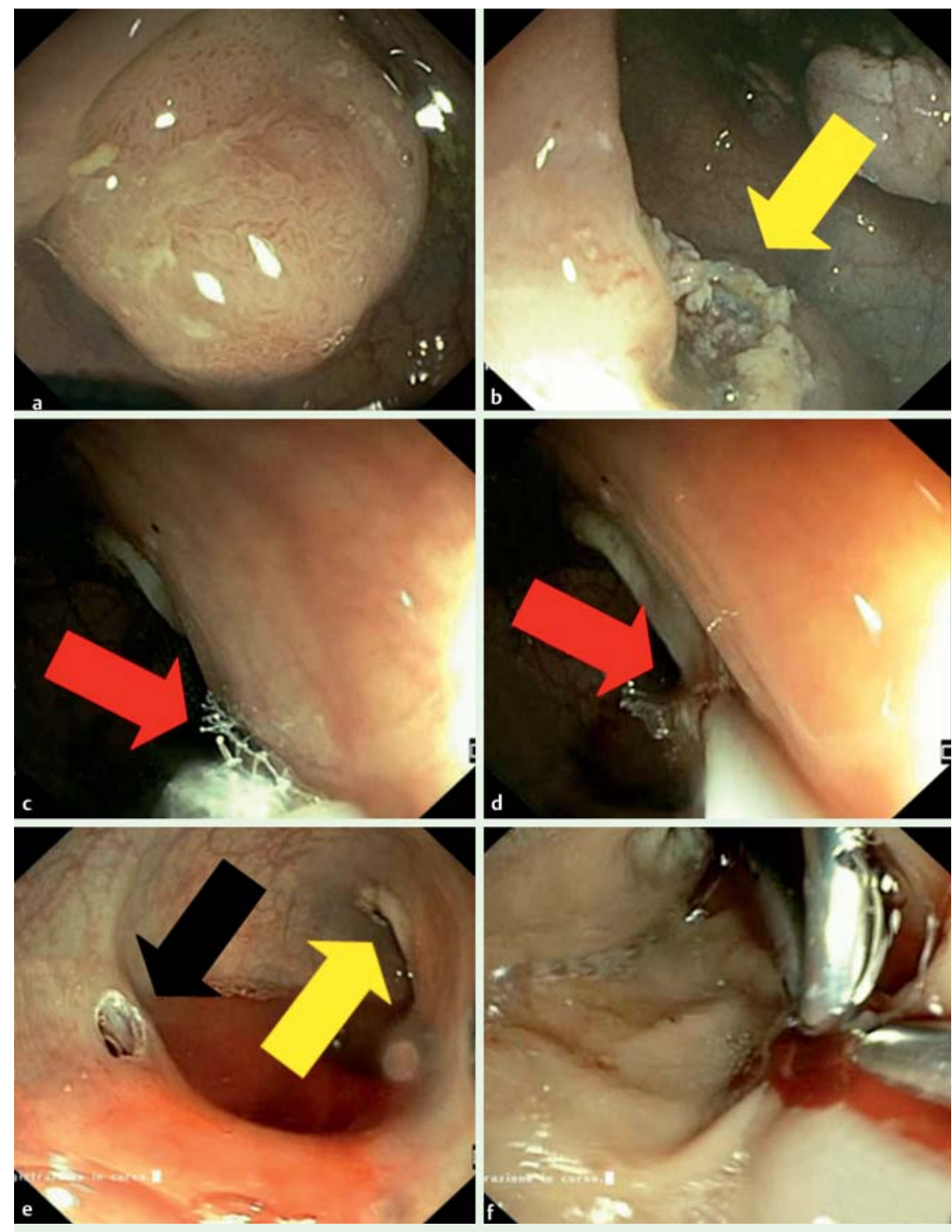

Fig. 1 Colonoscopic appearances in a 72-year-old woman undergoing polypectomy showing: a a large polyp in the sigmoid colon; $\mathbf{b}$ the base of the polyp (yellow arrow) after polypectomy had been performed; $\mathbf{c , d}$ a small amount of mucosa that was trapped within the net and cut off when the net was withdrawn into the sheath by a "guillotine effect" (red arrows); e a perforation in the wall of the colon (black arrow) opposite to the base of the polyp (yellow arrow); $\mathbf{f}$ endoscopic clips that were placed to close the perforation.

\section{Roberto Di Mitri, Filippo Mocciaro, Sandro Sferrazza, Rosalba Orlando, Vincenzo Costanza}

Gastroenterology and Endoscopy Unit, A.R.N.A.S. Civico-Di Cristina-Benfratelli Hospital, Palermo, Italy

\section{References}

1 Fisher DA, Maple JT et al. ASGE Standards of Practice Committee Complications of colonoscopy. Gastrointest Endosc 2011; 74: $745-752$

2 Kim JS, Kim BW, Kim JI et al. Endoscopic clip closure versus surgery for the treatment of iatrogenic colon perforations developed during diagnostic colonoscopy: a review of 115,285 patients. Surg Endosc 2013; 27: 501-504

\section{Competing interests: None}


3 Kirschniak A, Subotova N, Zieker D et al. The over-the-scope clip (OTSC) for the treatment of gastrointestinal bleeding, perforations, and fistulas. Surg Endosc 2011; 25: 2901 2905

4 ASGE TechnologyCommittee, Diehl DL, Adler $D G$ et al. Endoscopic retrieval devices. Gastrointest Endosc 2009; 69: 997-1003

\section{Bibliography}

Dol http://dx.doi.org/

10.1055/s-0034-1365097

Endoscopy 2014; 46: E169-E170

(C) Georg Thieme Verlag KG

Stuttgart · New York

ISSN 0013-726X
Corresponding author

Roberto Di Mitri, MD

Via Strada Ferrata 44/D 90046 Monreale (PA)

Italy

Fax: +39-091-6663053

robdimitri68@yahoo.it 